\title{
A Internet das Coisas e o Agronegócio no Brasil: um olhar sobre a produção científica brasileira na base Scopus
}

\author{
The Internet of Things and Agribusiness in Brazil: a look at brazilian \\ scientific production
}

\author{
Renata Luiza de Castilho Rossoni ${ }^{1}$ \\ André Luís Rossoni ${ }^{2}$ \\ João Carlos de Souza Maia ${ }^{1}$ \\ ${ }^{1}$ Universidade Federal de Mato Grosso, Cuiabá, MT, Brasil \\ ${ }^{2}$ Empresa Brasileira de Pesquisa Agropecuária - Embrapa Agrossilvipastoril, Sinop, MT, Brasil
}

\begin{abstract}
Resumo
Levar alimentos à mesa do consumidor com menor custo exige uma produção eficiente no uso dos recursos naturais, financeiros e de pessoal, e a adoção de tecnologias emergentes viabiliza este diferencial ao agronegócio. $\mathrm{O}$ uso integrado de tecnologias de produção e comunicação como a loT (internet of things) potencializa receber informações e gerir equipamentos para operacionalizar a produção agropecuária de forma remota, tornando a produção mais precisa e eficiente. Esta pesquisa guiou-se com o objetivo de identificar e mapear a produção científica das Instituições de Pesquisa Científica e Tecnológica e dos pesquisadores brasileiros no setor de agronegócio com a adoção ou potencial uso da IoT, tendo como objeto de estudo artigos da base Scopus, e como método de estudo a bibliometria. O estudo identificou um conjunto de 1039 autores, 267 instituições nacionais e internacionais que trabalham com o tema, o que possibilitou uma análise de cenários de pesquisa e discussão de novos gaps, para parceirias.
\end{abstract}

Palavras-chave: Agronegócio. Internet das Coisas. Pesquisadores. Instituições.

\begin{abstract}
Bringing food to the customers at a lower cost, requires efficient production in the use of natural resources, financial and personnel, the adoption of emerging technologies enables this differential to agribusiness. The integrated use of production and communication technologies such as IOT (internet of things) empowers to receive information and manage equipment to operationalize agricultural production remotely, making production precise and efficient. The research was guided with the objective of identifying the scientific production of Brazilian research institutions and researchers in the agribusiness sector with the adoption or potential use of IoT. The chosen method of study was bibliometry, this allows a metric analysis of the data studied, making it possible to identify researchers and institutions working in the country which made possible a scenario analysis and discussion of new gaps.
\end{abstract}

Keywords: Agribusiness. Internt of Things. Researcher. Institutions.

Área Tecnológica: Tecnologia. Agronegócio. Propriedade Intelectual. 


\section{Introdução}

O agronegócio é considerado um dos setores fundamentais para formação do PIB (produto interno bruto) brasileiro. No ano de 2017, segundo dados do IBGE (BRASIL, 2017), somente o segmento de agropecuária apresentou um crescimento de $13 \%$ em relação ao mesmo período do ano anterior. Para manter o crescimento e a produtividade com uso eficiente de recursos, os produtores buscam aumentar os investimentos em novas tecnologias de produção. Neste sentido, o agronegócio tem se mostrado muito competitivo, exigindo cada vez mais pesquisas que lhe forneçam meios de aumentar a produtividade por metro quadro com menores custos. Para atender a essa demanda, as empresas do agronegócio têm trabalhado cada vez mais com novas tecnologias, criando novos meios de produção para tornar o agronegócio mais eficiente. A produção integrada, agricultura de precisão, georreferenciamento, nanossensores e rastreadores destacam-se como tecnologias que abarcam essa evolução de produção no campo.

Os produtores rurais estão buscando a aplicação dessas tecnologias à agricultura, à produção pecuária e demandam informações e análises constantemente para o monitoramento da produtividade e controle de recursos. A adoção de tecnologias de comunicação em tempo real está auxiliando a gestão e a tomada decisão de forma mais rápida e precisa. O uso dessas tecnologias está baseado na transferência e análises de dados, destacando-se o uso abrangente da internet.

Dentre as tecnologias emergentes, a IoT (internet of things) é capaz de interligar os mais diferentes dispositivos à internet, inclusive possibilitando a coleta de dados desses dispositivos, tendo como consequência a maximização da produção rural, tanto em qualidade quanto em produtividade, pois com o seu uso o controle passa a ser em tempo real e as alterações e possíveis correções são apresentadas aos seus gestores em menor tempo. Em países mais desenvolvidos, a adoção da IoT tem apresentado maior ganho em produtividade e economia de recursos, o que melhora o desempenho financeiro das unidades produtivas (BRASIL, BNDES, 2017).

Contudo, antes de afirmar que a adoção de uma tecnologia emergente aumentará a produtividade ou reduzirá os custos de produção, faz-se necessário dispender esforços científicos no intuito de provar e certificar tais informações. Estes muitas vezes, ocorrem dentro das universidades e centros de pesquisas.

A relação de produção de tecnologias com os esforços científicos necessários para validá-la foi a base para o estudo detalhado da produção científica brasileira sobre a IoT e o agronegócio no Brasil. Tal inquietação surgiu a partir da discussão de Flávia Gubert, Mayara Pires Zanoto, Verena Alice Borelli e Gabriel Vidor, no artigo "Agronegócio: um olhar sobre a produção científica brasileira na Base Spell", publicado no II Simpósio Internacional de Inovação e Cadeias Produtivas do Agronegócio em 2017. Essa discussão norteou o objetivo principal desta pesquisa, que é o mapeamento da produção científica brasileira no setor de agronegócio com a adoção da tecnologia IoT no Brasil no período de 2000 a 2018, por meio da identificação de quem são os principais pesquisadores e instituições que mais publicam no país.

O método utilizado neste estudo é o de bibliometria, que pode ser entendida como um conjunto de leis e princípios estatísticos e matemáticos que têm por finalidade o mapeamento da produção científica (FONSECA, 1986). 
Quantificar as publicações e cooperações entre os pesquisadores, as instituições de pesquisa, a quantidade de autores por artigo e revistas que publicam sobre o tema, justifica-se pelo esforço de disseminar o conhecimento sobre as pesquisas e trabalhos que abordam adoção da IoT no agronegócio brasileiro. Esta pesquisa cria um panorama sobre as produções deste tema no Brasil, o que pode servir de base para novas pesquisas ou parcerias, fortalecendo ainda mais o agronegócio brasileiro.

A criação do mapa da pesquisa científica brasileira voltada à adoção da IoT no agronegócio possibilita uma visão detalhada dos estudos que ligam tecnologias inteligentes e o agronegócio, bem como apontar em que regiões e instituições estão estes trabalhos, quem são os principais atores desse novo cenário da produção de conhecimento e como eles se relacionam para levar mais eficiência e produtividade ao mercado de agronegócio do Brasil.

\section{Referencial Teórico}

\subsection{Agronegócio Brasileiro}

O agronegócio brasileiro passou por várias transformações, tanto em expansão de áreas produtivas como também pela adoção de novas tecnologias para o aumento da produtividade, o que faz com que este setor demande cada vez mais pesquisas nas mais diversas aplicações. Com a expansão para o cerrado, e a criação de novos sistemas de produção aliados à mecanização, uso de defensivos e fertilizantes químicos, os avanços da biotecnologia e da tecnologia de comunicação, o Brasil conquistou uma posição de destaque entre os maiores produtores de alimentos do mercado mundial.

Segundo o Instituto de Economia Agrícola (IEA) (SÃO PAULO, 2018), "[...] nos três primeiros trimestres de 2018, as exportações do agronegócio brasileiro aumentaram 7,3\% em relação ao mesmo período do ano anterior, alcançando $44,2 \%$ do total nacional. Já as importações do setor recuaram $1,3 \%$ no período, somando 7,8\% do total nacional".

Estes indicadores revelam o quanto o mercado agropecuário tem potencial para evoluir, uma vez que o crescimento da população mundial e os novos cenários socioeconômicos apontam para o aumento da demanda de alimentos, que deverão ser produzidos nas mesmas áreas já exploradas, porém, com aumento de produtividade e eficiência no uso de recursos naturais e econômicos. Tornar as unidades produtivas eficientes e autossuficientes é um dos grandes desafios para o setor. Aliar produção à novas tecnologias, uso consciente de recursos, mão de obra qualificada e tecnologias de comunicação simultâneas é o caminho a ser trilhado para os gestores do agronegócio. Para compreender a dimensão deste mercado faz-se necessário entender que o agronegócio é “... uma rede que envolve desde a produção e comercialização de insumos, passando pela própria produção agropecuária, até a transformação, distribuição e comercialização de produtos agropecuários" (BRASIL, 2009 p. 10). Heredia, Palmeira e Leite (2010, p. 160) afirmam que "O gerenciamento de um negócio que envolve muito mais que uma planta industrial ou um conjunto de unidades agrícolas é uma das tônicas da ideia de agronegócio". A adoção de novas tecnologias de produção levou o país a destacar-se em alguns produtos no mercado de exportação, segundo o Instituto de Economia Agrícola (IEA) (SÃO PAULO, 2018): 
Os cinco principais grupos nas exportações do agronegócio brasileiro, no acumulado de janeiro a setembro de 2018 foram: complexo soja (US\$33,65 bilhões), seguido por carnes (US $\$ 10,95$ bilhões), produtos florestais (US $\$ 10,49$ bilhões), complexo sucroalcooleiro (US $\$ 5,61$ bilhões), e cereais, farinhas e preparações (US $\$ 5,40$ bilhões). Esses cinco grupos agregados representaram $83,3 \%$ das vendas externas setoriais brasileiras, com destaque para o grupo do complexo soja que no período analisado aumentou sua participação de 37,6\% em 2017 para 42,4\% em 2018.

Estes dados revelam que o agronegócio do Brasil é uma fonte significativa de recursos para o país e uma oportunidade para investimentos para empresas e instituições que trabalham com inovação e tecnologias. Para aumentar a produtividade deste setor de relevante potencial são necessários investimentos também em transferência de tecnologias para que os novos conhecimentos, produtos e processos cheguem a todos os atores da cadeia do agronegócio. Os principais destinos das exportações do agronegócio brasileiro são apresentados no Gráfico 1 do Ministério da Agricultura, Pecuária e Abastecimento - MAPA (BRASIL, 2018), que coletou os dados de exportação até o mês de setembro de 2018.

Gráfico 1 - Exportações Brasileiras do Agronegócio por Mercado - 2018

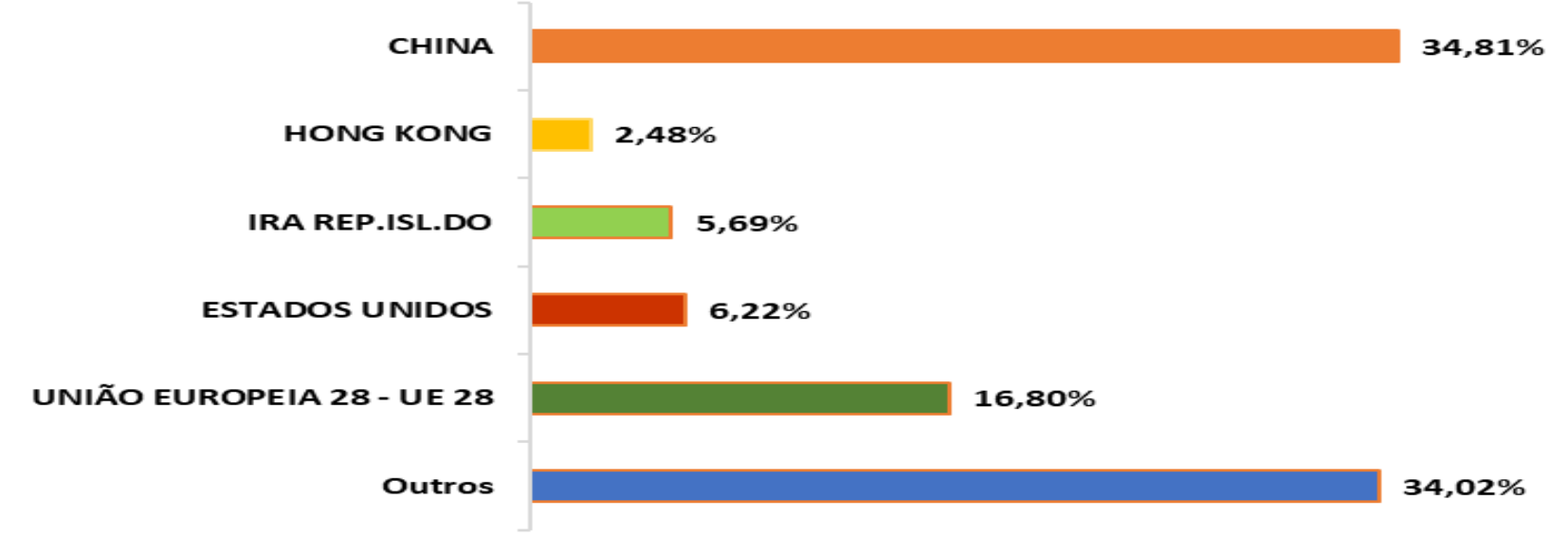

Fonte: BRASIL, MAPA (2018)

\subsection{Inovação}

Com um mercado cada vez mais competitivo e demandando por novos produtos e tecnologias, a inovação tem se tornado a palavra de ordem, para produtos, serviços e processos. Para Schumpeter (1988), a inovação tecnológica cria uma ruptura no sistema econômico, forçando uma alteração nos processos de produção e criando diferenciação entre empresas. Seguindo esta mesma analogia Drucker (1986) afirma que a inovação deve ser usada como uma ferramenta para explorar as mudanças no mercado, como oportunidades a serem aprendidas e praticadas.

A inovação deixa as empresas mais atrativas e competitivas, seja econômica ou produtivamente. O Manual de Oslo (2005 p. 41) afirma que:

Por meio da inovação, novos conhecimentos são criados e difundidos, expandindo o potencial econômico para o desenvolvimento de novos produtos e de novos métodos produtivos de operação. Esses melhoramentos dependem não apenas do conhecimento tecnológico, mas também de outras formas de conhecimento que são usadas 
para desenvolver inovações de produto, processo, marketing e organizacionais. Os tipos específicos de inovação podem diferir muito com relação a seus impactos sobre o desempenho da empresa e sobre a mudança econômica.

O conhecimento, que é a força motriz da inovação, aliado às tecnologias de comunicação cria um diferencial ainda mais competitivo e dinâmico ao mercado, demandando mais pesquisas para avaliar e certificar novos produtos, serviços e processos. Segundo Schefer e Carlomagno (2016, p. 46):

O que se busca hoje é a inovação aberta, a inovação em rede, a gestão de uma cadeia de inovação na qual a empresa se concentra naquilo que domina e inclusive terceiriza fases com outros agentes. A velocidade, ou a aceleração, com que os conhecimentos novos ultrapassam os anteriores impossibilita que uma empresa sozinha consiga acompanhar a evolução.

Dentro do agronegócio a inovação é um caminho a ser percorrido, uma vez que os recursos naturais estão cada vez mais limitados e a demanda de alimentos cresce consoante ao aumento populacional. Produzir mais com o uso eficiente de recursos, aliando a novas tecnologias, deve ser o novo processo incorporado ao perfil produtivo do campo e dos setores que trabalham com o agronegócio no Brasil.

\subsection{Tecnologias de Informação e Comunicação: Internet of Things (loT)}

O uso da tecnologia mudou o mundo. Da invenção da roda à criação da internet, a sociedade experimentou diversas revoluções nos processos produtivos. Hoje a tecnologia da informação e comunicação pode ser entendida como o conjunto de recursos tecnológicos usados de forma interligada com um objetivo em comum, que invadiu o cotidiano das pessoas. Segundo o IBGE (BRASIL, 2018):

Nas três últimas décadas, a dinâmica da economia mundial sofreu profundas transformações nos modelos de geração e acumulação de riqueza. Diferentemente do antigo padrão de acumulação baseado em recursos tangíveis, dispersos ao redor do mundo, no atual padrão, o conhecimento e a informação exercem papeis centrais, sendo as tecnologias de informação e comunicação seu elemento propulsor.

Ribeiro e Zorzal (2011) afirmam que na década de 90 (noventa) a criação da internet trouxe à comunicação e à informação maior velocidade, o que reduziu as distâncias entre algumas pessoas e organizações, mas sua popularização foi efetivada com a criação dos smartphones e tablets. Esses novos dispositivos, aliados a uma nova velocidade de transmissão de dados pela internet, criaram o um novo mercado e derrubaram as fronteiras físicas do mundo. Buscar informações tornou-se um processo rápido e muito prático. Os smartphones estão nas mãos de milhares de pessoas, coletando e disponibilizando informações continuamente. As comunicações e a transmissão de informações ocorrem em tempo real, o que significou um salto em produtividade para diversos setores, pois através das redes de dados muitas plantas industriais foram automatizadas e controladas a distância. 
No entanto a tecnologia que está demandando maior atenção de empresas e pesquisadores é a internet das coisas (internet of things - IoT), que pode ser entendida "como um ambiente de objetos físicos interconectados com a internet por meio de sensores pequenos e embutidos, criando um ecossistema de computação onipresente (ubíqua), voltado para a facilitação do cotidiano das pessoas, introduzindo soluções funcionais nos processos do dia a dia" (MAGRANI, 2018 p. 20). Com o uso da IoT, os equipamentos e máquinas trocam informações entre si. Por exemplo um sensor de umidade pode detectar a redução de umidade em uma determinada área de produção e enviar uma mensagem para o equipamento de irrigação apontando que aquela área verificada precisa receber um volume de água preciso. Ou ainda, seu veículo pode informar que você está a caminho de sua casa e seu aparelho de ar-condicionado se autoligar, para que, quando você entre em sua casa, ela esteja na temperatura que lhe agrade. Essa intercomunicação torna o uso de recursos mais eficientes, evitando desperdícios e minimizando custos. Para Rozsa, Dutra, Pinto e Muriel-Torrado (2017, p. 256), os objetos ligados por IoT;

[...] são capazes de coletar grandes quantidades de dados sobre as pessoas e o ambiente $e$, assim, poderem responder de maneira autônoma a determinadas situações ou disponibilizar informações que aumentam a percepção das pessoas sobre o contexto ao seu redor. Diante disso, podemos deduzir que o insumo principal na IoT é a informação, que é gerada e consumida tanto pelas pessoas quanto pelos objetos "inteligentes".

Consolidar um panorama acerca da adoção da internet das coisas no setor do agronegócio possibilitará a coleta de dados mais precisos como, índices pluviométricos em diversas áreas de produção e meses do ano, informar o consumo de combustível por máquina em cada atividade desenvolvida por esta, bem como a produtividade por metro quadro e o seu custo, e o consequente retorno para o produtor, o que tornará as unidades produtivas mais competitivas.

A adoção do IoT pelo agronegócio brasileiro pode ser descrita como diferencial de competitividade por outros países desenvolvidos. A EMBRAPA (BRASIL, 2017), ainda afirma que:

Para o Brasil, a Internet das Coisas é uma oportunidade formidável para alavancar o agronegócio nacional e o país está posicionado para capturar todo o seu valor. Prevê-se que, até 2025, a IoT terá um impacto econômico maior do que a robótica avançada, tecnologias cloud e até mesmo do que a internet móvel. Estima-se que até esse ano, o emprego de IoT no campo e o impacto do uso das soluções nesta área alcance entre US $\$ 5$ bilhões e US $\$ 21$ bilhões, apoiando queda de até $20 \%$ no uso de insumos agrícolas e alta de até $25 \%$ na produção das fazendas. A nível nacional e em todas as outras áreas, o impacto esperado no Brasil é ainda maior estimado entre US\$50 a 200 bilhões por ano, o que representa cerca de $10 \%$ do PIB do nosso país.

A IoT aplicada ao agronegócio permitirá uma análise multidimensional, detalhada das variáveis da produção no campo, oferendo ao produtor uma ferramenta mais precisa para a tomada de decisão, o que pode resultar em maior produtividade, uso eficiente de recursos $e$ menores impactos ambientais. 


\section{Processo Metodológico}

Esta é uma pesquisa descritiva, que "têm como objetivo a descrição das características de determinada população ou fenômeno" (GIL, 2017, p. 26), pois busca descrever e estudar as relações dos pesquisadores da área de agronegócio com o uso IoT. Também é exploratória, pois parte de uma busca de informações que levem o pesquisador a ter familiaridade com tema estudado. Por ter caráter descritivo e exploratório, adotaram-se procedimentos de pesquisa bibliográfica por esta ter como objeto de estudo artigos relacionados ao tema: internet das coisas e o agronegócio no Brasil, sendo a bibliometria o método escolhido como estratégia de análise dos dados coletados na pesquisa. Segundo Araújo (2006, p.12), a bibliometria é uma "técnica quantitativa e estatística de medição dos índices de produção e disseminação do conhecimento científico", mesmo sendo um método criticado por alguns pesquisadores, como Matos (2004, p. 5), que reconhece a importância da bibliometria, porém chama a atenção para a formulação adequada do propósito da pesquisa em relação aos números que ela apresentará.

Há uma maneira de olhar os números que encanta olhos positivistas. Ir desses números
intuitivamente para a conclusão de algo certamente não seria científico. A partir deles
começar uma discussão? "Começar" significa estruturar? Se sim, estamos de volta
ao problema de assumir estruturas conceituais por trás dos números, não justificadas
previamente. Se não, estamos diante de uma espécie de isca para prosseguimento do
trabalho investigativo. E aí, tudo bem, esses "números curiosos" serão apenas uma
dentre muitas coisas com que o cientista observador se depara no mundo "em estado
bruto", que chamam sua atenção e sobre as quais começa uma investigação empírica
ou filosófica.

Tal afirmação justifica o objetivo desta pesquisa, que é mapear os autores, instituições e parcerias que se dedicam ao estudo do uso da IoT no agronegócio brasileiro, e fornecer informações que possam ser úteis a grupos de pesquisas que queiram desenvolver ou potencializar suas infraestruturas de pesquisa.

Por se tratar de estudo sobre os pesquisadores e suas instituições, aplica-se a Lei de Lotka, que, segundo Rodrigues e Vieira (206, p. 169), "analisa a produtividade científica dos autores, ou seja, verifica a contribuição de cada um para o desenvolvimento científico em sua área de conhecimento". A lei de Lotka também é conhecida como a lei dos quadrados inversos. Lokta, em 1926, ao desenvolver seu estudo demonstrou que apenas um pequeno grupo de autores é responsável por um grande volume de literatura de uma determinada área, e que um grande número de pequenos autores se iguala a um pequeno grupo de grandes autores, em produções, justificando a necessidade de estudá-los.

Na primeira etapa, foi escolhida a base Scopus como base de pesquisa para analisar a produção científica dos autores que trabalham com o tema agronegócio com uso de IoT. Esta base possui a característica de armazenar conjuntos de materiais científicos de várias áreas do conhecimento. Para a segunda etapa foram criados os parâmetros para buscas, delimitação $e$ cobertura. Como o uso da IoT no agronegócio do Brasil ainda é um tema recente, optou-se por fazer as buscar entre os anos 2000 a 2018, trabalhando com limitação de território Brasil, com acesso livre. 
Como parâmetro de busca foi escolhido um conjunto de palavras que foram buscadas no abstract, título e palavras-chaves dos artigos. O critério de busca no campo abstract, na referida base, justifica-se por este apresentar o resumo da pesquisa, apresentando uma breve descrição o tema e o objetivo e objeto de pesquisa. Para as palavras selecionadas escolheu-se idioma inglês, por este abranger um número maior de trabalhos publicados, as palavras foram escolhidas através da pesquisa em publicações de autores que trabalham com a temática de agricultura de precisão, em outros países como Estados Unidos, Canadá e China que apresentam maiores números em publicações na área, para realização das buscas além das palavras apresentadas na Tabela 1, foram utilizados os operadores Booleanos: END, OR e NOT para ampliar o campo de buscas.

Tabela 1 - Palavras Selecionadas para a Realização de Buscas na Base Scopus

\begin{tabular}{cc} 
PALAVRAS PARA BUSCAS & \\
SMART AGRICULTURE & PRECISION AGRICULTURE \\
SMART FARMING & COMUNICATION TECHNOLOGY \\
FARM MANAGEMENT INFORMATION SYSTEM & DIGITAL SOIL MAPPING \\
BIG DATA & AGRIBUSINESS \\
AGRICULTURE & TRACKERS \\
INTERNET OF THINGS & EMERGING TECHNOLOGY \\
PRECISION FARMING & EFFICIENCY \\
AGRICULTURAL INNOVATION & CLOUD DATA PROCESSING \\
INFORMATION TECHNOLOGY & REMOTE MONITORING \\
SENSORS & MACHINE LEARNING \\
\hline
\end{tabular}

Fonte: Dados da pesquisa (2018)

Após a primeira seleção de artigos nas bases de dados esses, foram tratados de forma a analisar a aderência com o tema, posteriormente estes foram organizados em tabela no Excel da Microsoft por critérios de título autor, coautores, instituições, ano, periódico e palavras. Os dados, depois de organizados, foram tratados no software Vosviewer, disponibilizado no site vosviewer.com, por ser um software não comercial, o que viabiliza a pesquisa.

Na primeira etapa de buscas na base Scopus, foram selecionados 751 artigos, em 18 buscas utilizando as palavras selecionadas de forma combinada com o uso de operadores boleanos e com buscas simples por um termo específico para o tema. Alguns termos e combinações não apresentaram resultados quando aplicado o filtro território Brasil, como: Farm AND management AND, information system; agriculture AND trackers; agriculture AND cloud data processing, reduzindo o campo de cobertura da pesquisa e, consequentemente, apresentando uma lacuna para pesquisas. 
Realizada a seleção inicial, foram selecionados 462 artigos que possuem alguma vinculação com o tema. A IoT, por ser uma temática nova principalmente no agronegócio brasileiro, representa um déficit de pesquisa no Brasil. Para buscar um resultado mais abrangente, optou-se por fazer uma análise de aderência ao tema, através da combinação de processos, técnicas e modelos apresentados nos trabalhos que podem usam ou podem vir a usar de tecnologias de comunicação e, principalmente, a IoT.

Após esta triagem utilizou-se o software Vosviewer para analisar os 462 trabalhos com o objetivo de identificar seus autores e instituições de pesquisa. Após aplicação do tratamento de dados duplicados ou com erro de transcrição ficaram 367 artigos, identificando-se, nestes, 1.039 autores que trabalham com atividades que envolvem o setor do agronegócio e tecnologias de comunicação.

\section{Resultados e Discussão}

Ao relacionar o quantitativo de artigos publicados na base por autor, constata-se o fator apresentado na Lei de Lotka, onde um pequeno grupo de autores é responsável por uma quantidade significativa de trabalhos dentro do conjunto analisado, enquanto um grande número de autores é responsável por uma quantidade menor de trabalhos no mesmo conjunto. O Gráfico 2 representa essa distribuição dentro do estudo, onde apenas 23 autores possuem mais de 03 trabalhos publicados, e 101 autores possuem de 02 ou três trabalhos publicados. O maior grupo apresentou 914 autores com uma publicação por autor. A forma de funil permite visualizar o estreitamento no quantitativo de produção publicada na base Scopus por autor.

Grafico 2 - Produção Publicada por Autor na Base Scopus 2000-2018

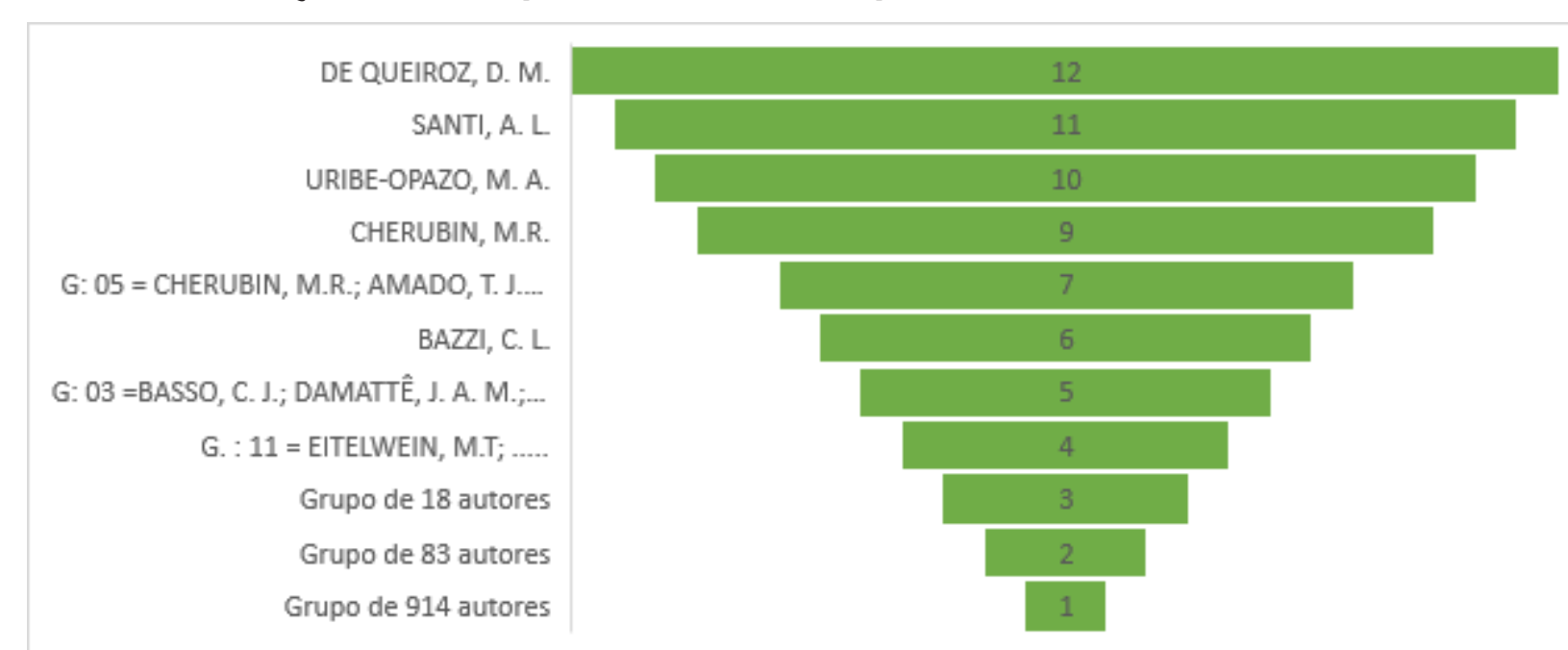

Fonte: Dados da pesquisa (2018)

Esse grupo de pesquisa mantém uma rede de cooperação com 141 instituições nacionais e 126 instituições internacionais criando uma rede de colaboração que fomenta o desenvolvimento de pesquisas, o que pode ser constatado na Figura 1. 
Figura 1 - Redes e Clusters de Pesquisadores

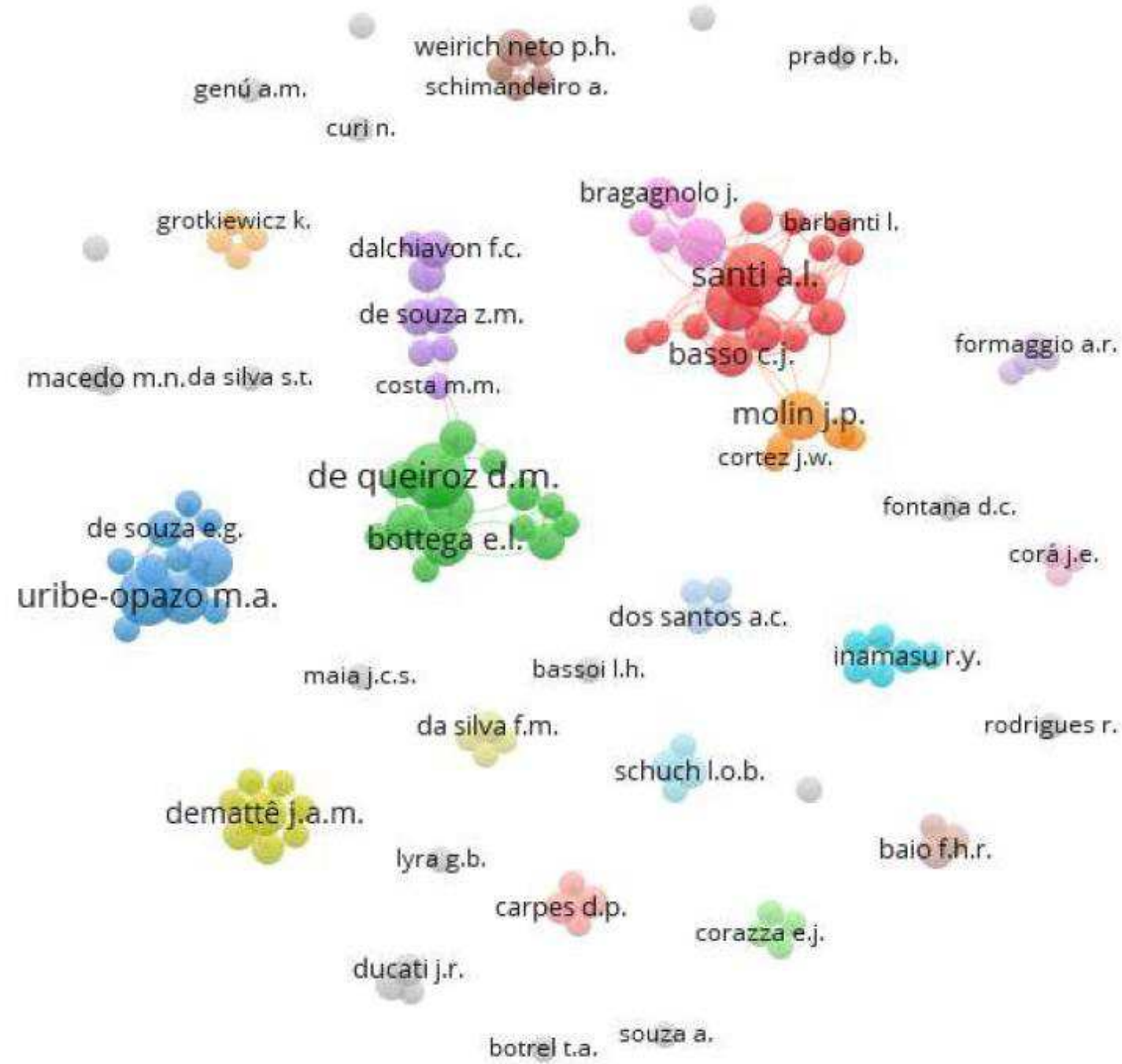

Fonte: Dados da pesquisa (2018)

A concentração de um grande número, de produção por poucos autores faz com que se crie clusters de produção. No Brasil estes clusters possuem comportamento isolado formando poucas redes de conhecimento e pesquisas. Quanto maior a relação entre os autores, mais detalhada e crítica são as pesquisas. As redes de pesquisa permitem, além de troca de informações e conhecimento, o surgimento de novas descobertas e integração de áreas para inovação e desenvolvimento econômico e social da população.

A troca de conhecimento e tecnologias é uma prioridade para instituições de ensino $e$ pesquisa tanto públicas quanto privadas no Brasil. Com as distâncias e diversidades que o território brasileiro oferece as redes de pesquisas criadas entres as instituições possibilitam o uso compartilhado de algumas tecnologias e propagação do conhecimento. O Brasil concentra em alguns Estados um número maior de instituições de pesquisa e apoio. A pesquisa revelou o quantitativo de instituições que trabalham com o agronegócio e a IOT por Estado: São Paulo 
tem 18 instituições de pesquisa e apoio a pesquisa, seguido do Rio Grande do Sul com 16; Minas Gerais com 13; Paraná e Distrito Federal com 12; e Rio de Janeiro com 10 instituições. Os demais Estados apresentaram um número inferior a 10 instituições (Figura 2). Destaca-se, neste contexto, a relevância das instituições de ensino e pesquisa para o fortalecimento do desenvolvimento do setor do agronegócio para o país. Em alguns Estados a pesquisa é desenvolvida somente por universidade públicas. A pesquisa revelou que o Brasil tem regiões em que a temática ainda não está sendo pesquisada de forma acentuada, o que possibilita a expansão das redes de pesquisas e conhecimentos para estas regiões visando ao desenvolvimento de novas pesquisas na área.

Figura 2 - Distribuição das Instituições que trabalham com os temas Agronegócio e IOT

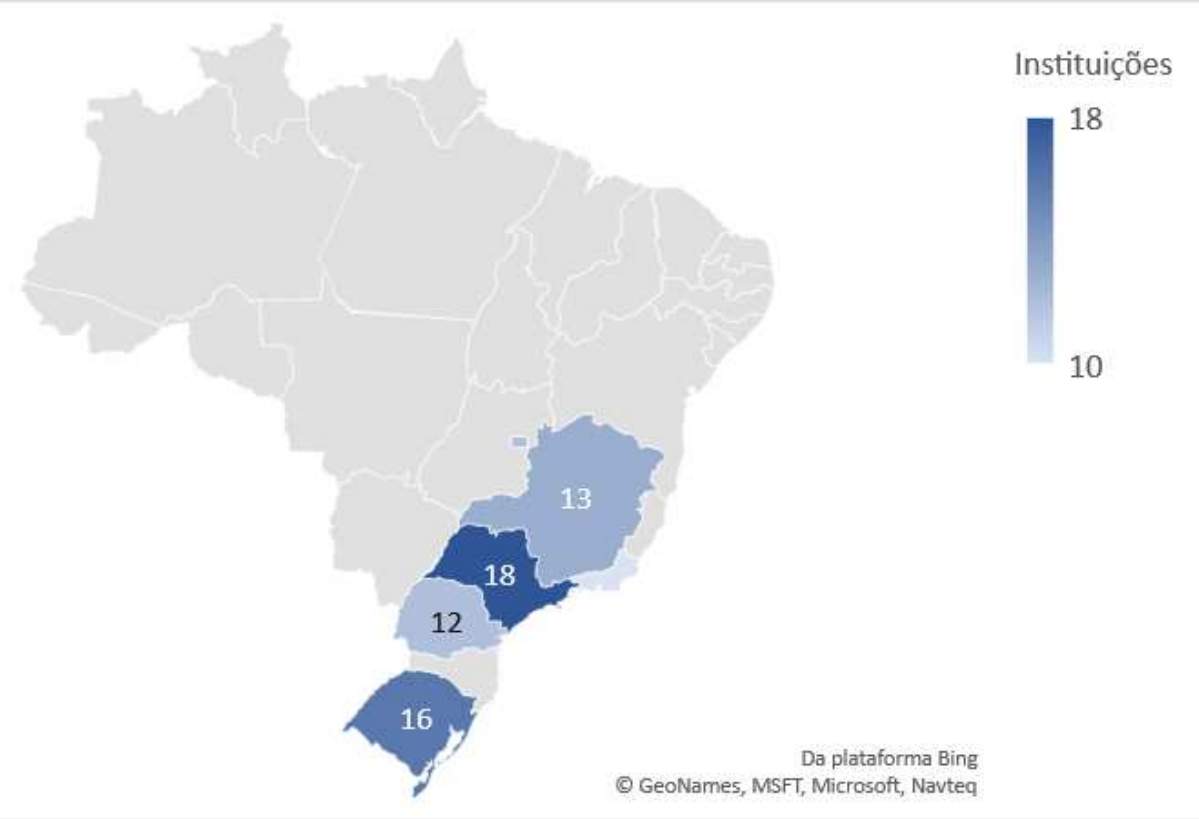

Fonte: Dados da Pesquisa (2018)

O uso compartilhado de tecnologias e conhecimento nas áreas de IoT e agronegócio mostrou-se eficiente na pesquisa. Dentre os 1.039 autores estudados, identificou-se que eles estão distribuídos em 142 instituições nacionais e/ou instaladas no Brasil. A concentração de um grande volume de pesquisa por poucas instituições é um fator a ser discutido para o incremento de pesquisas e novas parcerias. Para o detalhamento deste fator foram ranqueadas instituições com produção entre 55 a 10 trabalhos por unidade. Com este critério observou-se que apenas um pequeno grupo de 15 instituições é responsável por aproximadamente $58 \%$ por trabalhos analisados. O Gráfico 3 destaca o volume de produção por instituições para este recorte de produção/instituição. 
Gráfico 3 - Comportamento de Produção por Instituição

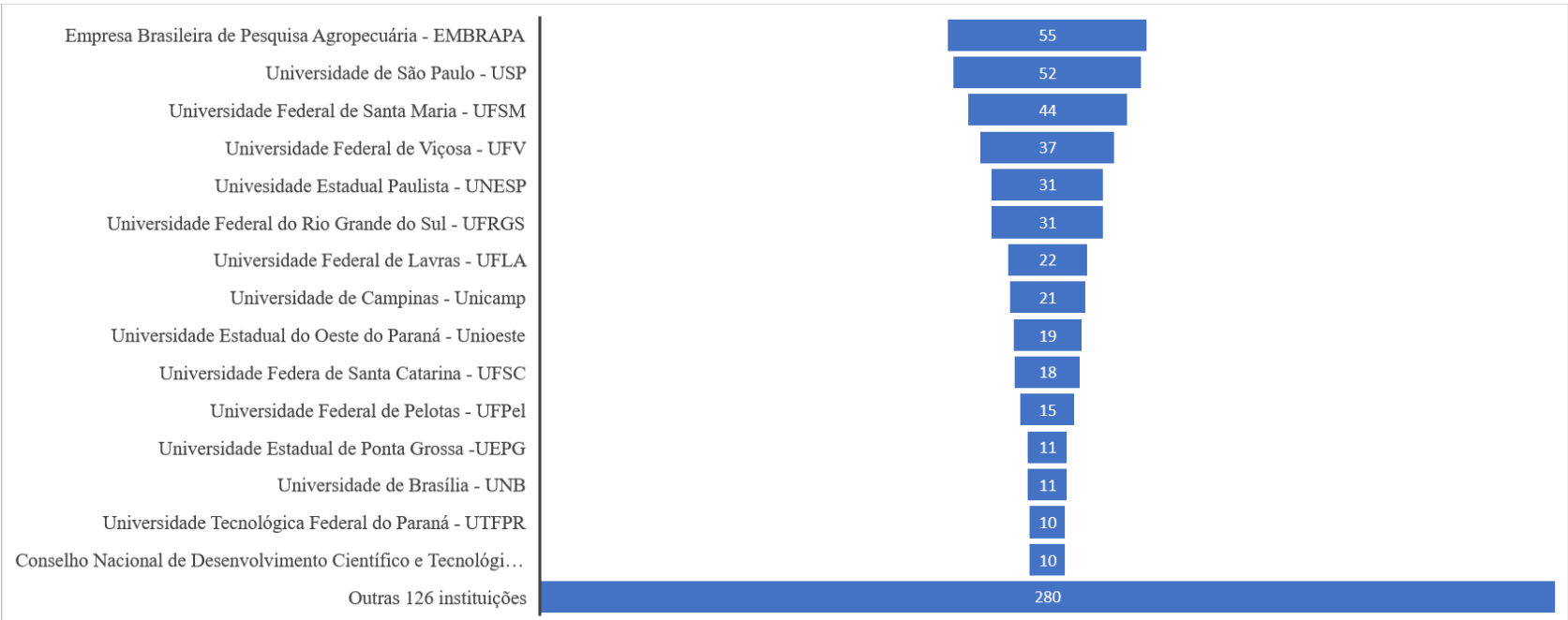

Fonte: Dados da Pesquisa (2018)

O comportamento observado na produção por autores também se apresenta ao se analisar a produção por instituição, onde um pequeno grupo é responsável por um grande volume de trabalhos, ressaltando-se que este comportamento também delimita geograficamente a alocação do conhecimento e o desenvolvimento de pesquisas no país, pois não há uma rede forte ligando nacionalmente todos os clusters de pesquisas.

E este comportamento também se repete ao se estudar as relações internacionais das instituições e seus autores: dentro dos trabalhos selecionados para a pesquisa foi possível constatar parcerias com 38 países (Figura 3).

Figura 3 - Países parceiros do Brasil em pesquisas e quantidade de trabalhos realizados

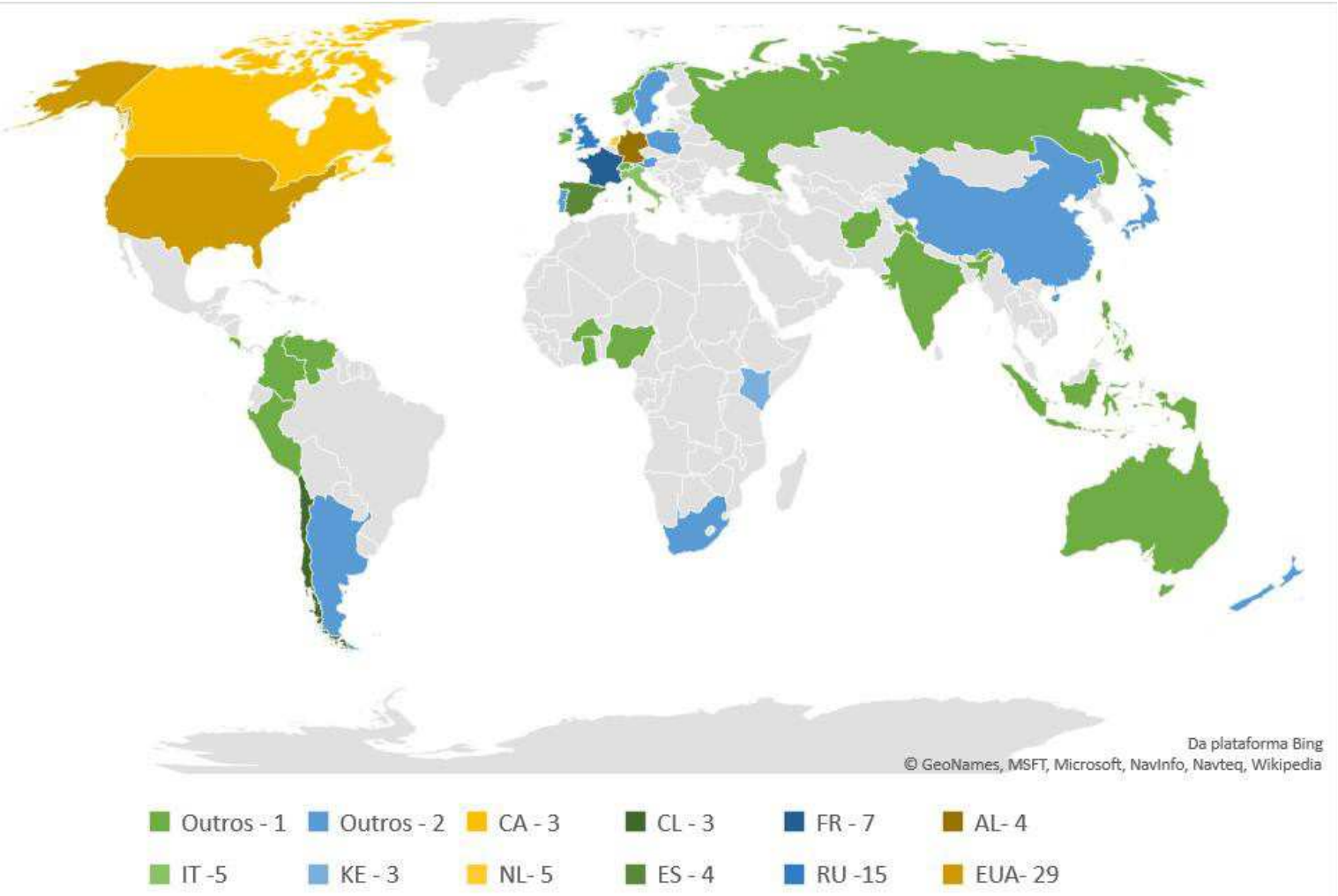

Fonte: Dados da Pesquisa (2018) 
A Figura 3 traz um panorama dos países parceiros do Brasil nas pesquisas sobre o uso de tecnologias de comunicação e IoT no agronegócio brasileiro. Destacam-se nestas relações as parcerias realizadas com os Estados Unidos da América, que apresentou um volume de 29 trabalhos compartilhados, seguido do Reino Unido com 15 trabalhos compartilhados, França com 7 trabalhos e Itália e Países Baixos com 5 trabalhos compartilhados. Estes cinco países representam mais de $50 \%$ das redes de colaboração de pesquisas que o Brasil mantém na área de agronegócio com uso de IoT. Essas redes de colaboração são relevantes para o desenvolvimento de novas tecnologias e produtos, uma vez que países como Estados Unidos, Reino Unido e França já exploram o uso de IoT em suas redes de agronegócio. Ainda neste contexto verifica-se um gap para a expansão de redes de conhecimentos e uso de tecnologias com países como Japão, Suécia, China e Alemanha, que são tecnologicamente mais eficientes que o Brasil. A troca de conhecimento e uso de tecnologias permite ao Brasil desenvolver produtos e processos com base nas características e condicionantes locais para atender às demandas internas do país.

\section{Considerações Finais}

O uso de tecnologias emergentes no agronegócio brasileiro é recente, o que justifica o pequeno número de autores que tratam diretamente com o tema e a restrição no quantitativo de trabalhos na área.

A concentração de autores e instituições de pesquisa nas regiões Sudeste, Centro-Oeste e Sul do país identificadas no estudo bibliométrico justifica-se por estas serem regiões mais desenvolvidas economicamente e tecnologicamente e, por isto, comportam maior população e diversidades de conhecimento e economias, demandando mais pesquisadores e instituições.

Embora o PIB do país indique as atividades de produção do agronegócio como relevantes para o desenvolvimento nacional, a produção de conhecimento científico para o desenvolvimento dessas áreas encontra-se em sentidos opostos: enquanto a exploração agropecuária é ampla, a produção de conhecimento encontra-se mais centralizada em regiões cuja atividade econômica principal não é a produção do agronegócio.

Para cobrir a lacuna geográfica do conhecimento científico no país, instituições e autores estão buscando ampliar suas redes de relacionamentos e assim desenvolver e compartilhar tecnologias e conhecimentos para fortalecer os resultados de seus trabalhos. $\mathrm{O}$ mapeamento das oportunidades e desafios para adoção efetiva da IoT no agronegócio brasileiro passa pelo aumento dessas redes de conhecimento e tecnologias. Alavancar os estudos sobre a adoção dessas tecnologias e seus resultados é fundamental para implantar a cultura de inovação na base do agronegócio, pois antes do mercado adotar um novo processo ou produto, ele necessita da validação científica do mesmo.

O estudo bibliométrico dos artigos publicados na base Scopus que abordam o uso, ou potencial uso, de tecnologias de comunicação como a IoT revelou um gap para trabalhos que venham a explorar as tecnologias adotadas no agronegócio brasileiro e suas origens nas bases de patentes e mesmo o mapeamento do uso das tecnologias nacionais e o estudo sistêmico dos trabalhos produzidos pelas redes de autores e instituições.

Destaca-se nas discussões a relevância da Embrapa e da USP para o desenvolvimento do setor em relação ao uso de tecnologias. Essas instituições são referências nacionais em pro- 
dução científica e tecnológica. Os principais autores destacados na bibliometria estão ligados a estas instituições formando os clusters de conhecimento mais representativos do país. Estes autores e suas instituições também encabeçam as redes de conhecimentos entre o Brasil e diversas instituições de pesquisas no mundo. Outro fato relevante são as produções em parcerias com os Estados Unidos e o Reino Unido, que são países que possuem aplicação mais eficiente de tecnologias emergentes e IoT na produção do agronegócio. $\mathrm{O}$ baixo volume de pesquisas realizadas em parceria com países como Japão, Suécia e China apresenta uma janela para a construção de redes mais representativas com estes, futuramente.

A troca de conhecimento e tecnologias que as redes de conhecimento científico proporcionam aos pesquisadores, instituições e aos países envolvidos cria um leque de oportunidade e desafios a serem mapeados e investigados para guiar o desenvolvimento econômico e social da população mundial, de forma mais igualitária.

O estudo bibliométrico pode ser usado como uma ferramenta investigativa e de prospecção para novos trabalhos. As leis e modelos que a bibliometria oferece para estudo demostram grande eficiência para análises, direcionamento e projeções de pesquisa nas mais diversas áreas do conhecimento, revelando oportunidades e gaps de pesquisas.

\section{Referências}

ARAÚJO, Carlos Alberto. Bibliometria: Evolução histórica e questões atuais. Em Questão, Porto Alegre, v. 12, n. 1, p.11-32, 2006. Semestral. Disponível em: https://seer.ufrgs.br/EmQuestao/article/ view/16. Acesso em: 14 out. 2018.

BRASIL. Banco Nacional de Desenvolvimento Econômico e Social - BNDES. Internet das Coisas: um plano de ação para o Brasil. Produto 8: relatório de plano de ação-iniciativas e projetos mobilizadores. Disponível em: https://www.bndes.gov.br/wps/portal/site/home/conhecimento/ pesquisaedados/estudos/estudo-internet-das-coisas-iot/estudo-internet-das-coisas-um-plano-de-acaopara-o-brasil. Acesso em: 08 out. 2018.

BRASIL. Empresa Brasileira de Pesquisa Agropecuária - EMBRAPA. Internet das coisas (IoT): inovação tecnológica em apoio ao agronegócio. Série diálogos estratégicos - Observatórios (NT7). Brasília: 2017. 11 p.

BRASIL. Empresa Brasileira de Pesquisa Agropecuária. Pesquisador, Paulo e Cruvinel. Agronegócio e oportunidades para o desenvolvimento sustentável do Brasil. Serie documentos, ISSN15187179; 44. São Carlos: Embrapa Instrumentação Agropecuária: 2009. 19p.

BRASIL. Instituto Brasileiro de Geografia e Estatística - IBGE. Puxado pela agricultura, PIB cresce 1,0\% em 2017 e chega a R\$ 6,6 trilhões. Disponível em: https://agenciadenoticiasi.ibge. gov.br/agencia-noticias/noticias/208-puxado-pela-agricultura-pib-cresce-1-0-em2017-e-chega-a-r-6-6trilhoes. Acesso em: 23 out. 2018.

BRASIL. Instituto Brasileiro de Geografia e Estatística - IBGE. O Setor de Tecnologia da Informação e Comunicação no Brasil. Disponível em: https://www.ibge.gov.br/estatisticasnovoportal/multidominio/ciencia-tecnologia-e-inovacao/9139-o-setor-de-tecnologia-da-informacaoe-comunicacao-no-brasil.html? =\&t=o-que-e. Acesso em: 3 nov. 2018. 
BRASIL. Ministério da Agricultura, Pecuária e Abastecimento - MAPA. Estatísticas de Comércio Exterior do Agronegócio Brasileiro. Indicadores Gerais Agrostat. Disponível em: http:// indicadores.agricultura.gov.br/index.htm. Acesso: 31 out. 2018.

BRASIL. Instituto de Pesquisa Econômica Aplicada - IPEA. O impacto do investimento direto estrangeiro no crescimento da economia brasileira. A Revista Planejamento e Políticas Públicas (PPP). Disponível em: http://www.ipea.gov.br/ppp/index.php/PPP/index. Acesso em: 27 out. 2018.

CRUZ, Marcia Rohr da; Severo, Eliana Andrea; GUIMARÃES, Júlio Cezar Ferro. Inovação e tecnologia no agronegócio como alternativa para a economia no Brasil. Caxias do Sul: Educs, 2017. p. 189-204.

DRUCKER, PETER F. Inovação e Espírito Empreendedor - Entrepreneurship. 6 ed. São Paulo: Pioneira, 1986. 378 p.

FONSECA, Edson Nery da. Bibliometria: teoria e prática. São Paulo: Cultrix, 1986. 141 p.

GIL, Antônio Carlos. Como elaborar projetos de pesquisa. 6. ed. São Paulo: Atlas, 2018. 173 p.

GUBERT, Flavia; ZANOTTO, Mayara Pires; BORELLI, Verena Alice; VIDOR, Gabriel. Agronegócio: um olhar sobre a produção brasileira na base Spell. In: CRUZ, Márcia Rhor; SEVERO, Eliana Andrea; GUIMARÃES, Júlio César Ferro. Inovação e Tecnologia no Agronegócio como Alternativa para Economia Brasileira. Anais [...] II Simpósio Internacional de |Inovação em Cadeias Produtivas do Agronegócio - SICPA. Caxias do Sul: Educs, 2017. p. 189 - 204.

HEREDIA, Beatriz; PALMEIRA, Moacir; LEITE, Sérgio Pereira. Sociedade e Economia do Agronegócio no Brasil. Revista Brasileira de Ciências Sociais, São Paulo, v. 25, n. 74, p. 159176, 2010.

MAGRINI, Eduardo. Internet das coisas. Rio de Janeiro: FGV Editora, 2018.

MATOS, Pedro Lincoln C. L. de. Bibliometria: A metodologia convencional em questão. Revista de Administração de Empresas. São Paulo, v. 3, n. 2, p.1-6, 2004. Semestral. Disponível em: http:// www.rae.com.br/eletronica/index.cfm?FuseAction $=$ Artigo\&ID $=2199 \& S e c a o=D E B A T E \& V o l u m$ $e=3 \&$ Numero $=2 \& A n o=2004$. Acesso em: 11 out. 2018 .

OCDE - Manual de Oslo: propostas para coleta e interpretação de dados para inovação. 3. ed. Tradução; Finep. São Paulo: Finep, 2005.

RIBEIRO, Marcos e ZORZAL, Ezequiel. Realidade virtual e aumentada: aplicações e tendências. Uberlândia: Editora SBC, 2011.

RODRIGUES, Charles; VIERA, Angel Freddy Godoy. Estudos bibliométricos Sobre a Produção Científica da Temática Tecnologias da Informação e Comunicação em Bibliotecas. Revista de Ciência da Informação e Documentação, Ribeirão Preto, v. 7, n. 1. p.167-180, 2016. Semestral. Disponível em: http://www.revistas.usp.br/incid/article/view/98761. Acesso em: 14 out. 2018.

ROZSA, Vitor; DUTRA, Moisés Lima; PINTO, Adilson Luiz; MURRIEL-TORRADO, Enrique. O Paradigma Tecnológico da Internet das Coisas e sua Relação com a Ciência da Informação. Informação e Sociedade: Estudos, João Pessoa, v. 27, n. 3, p. 255-266, 2017. Quadrimestral. Disponível em: http://periodicos.ufpb.br/index.php/ies/article/view/36975. Acesso em: 05 set. 2018. 
SÃO PAULO. Instituto de Economia Agrícola - IEA. Secretaria de Agricultura e Abastecimento do Estado de São Paulo. Balança Comercial dos Agronegócios Paulista e Brasileiro de Janeiro a setembro de 2018. Disponivel em: http://www.iea.sp.gov.br/out/TerTexto.php?codTexto=14520. Acesso em: 26 out. 2018.

SCHERER, Felipe Ost; CARLOMAGNO, Maximiliano Selister. Gestão da Inovação na Prática: Como aplicar conceitos e ferramentas. 2. ed. São Paulo: Atlas, 2016. 206 p.

SCHUMPETER, Jhoseph Alois. A Teoria do Desenvolvimento Econômico. São Paulo: Nova Cultural, 1988. 168 p.

\section{Sobre os Autores}

\section{Renata Luiza de Castilho Rossoni}

E-mail: renatalcrossoni@gmail.com

Mestranda em Propriedade Intelectual e Transferência de Tecnologia para Inovação pela Universidade Federal do Mato Grosso.

Endereço profissional: Rua Guaxupé, n. 43, Jardim Belo Horizonte, Caixa Postal 423. CEP 78556-296.

\section{André Luís Rossoni}

E-mail: andre.rossoni@embrapa.br Mestre em Gestão Agroindustrial pela Universidade Anhanguera-Uniderp.

Endereço profissional: Rodovia dos Pioneiros MT-222, Km 2,5, Zona Rural Caixa Postal: 343, Sinop, MT. CEP: 78550-970.

\section{João Carlos de Souza Maia}

E-mail: jotace@terra.com.br

Doutor em Engenharia Agrícola pela Universidade Estadual de Campinas.

Endereço profissional: Centro de Agrárias. Av. Fernando Corrêa da Costa, n. 2.367, Bairro Boa Esperança. Cuiabá, MT. CEP: 78060-900. 